\title{
Die toepassing van stygende pryspeilveranderinge by kapitaalinvesteringsbesluite
}

\author{
Sarah S. Visser \\ Departement Bedryfsrekeningkunde, Potchefstroomse Universiteit vir $\mathrm{CHO}$, Potchefstroom
}

\begin{abstract}
The application of increasing price-level changes to capltal in. vestment decialons. Inflation (the decreasing purchasing power of money) has become a reality with which one has to live, and for which one has to plan. As a result of the decrease in the purchasing power of money, the prices of production means are going up considerably, and more so where longterm capital projects are involved.

The initial investment in respect of a capital project involves the least risk in accuracy, as it has to be known at the moment of decision-making and cannot be changed significantly until the decision has been realized.

The other factors essential for decision-making and which will be realized in the future throughout the lifespan of the asset are subject to change in the value of money and it is important that the influence of this change be taken into account.

The impact of price-level changes can be taken into account through the use of general or specific price-level changes. The application of this has led to the fact that only general pricelevel changes, or only specific price-level changes, or general and specific price-level changes can be used for the adjustment of items. The last includes the advantages of using both price-level changes. In each of these applications different methods have been developed which agree in principle, while there may be differences with regard to details of the applications.

S. Afr. J. Bus. Mgmt. 1984, 15: 140-143
\end{abstract}

Die dalende koopkrag van geld of te wel inflasie het 'n werklikheid geword waarmee saamgeleef en waarvoor beplan moet word. As gevolg van die dalende koopkrag van geld, styg die pryse van produksiemiddele aansienlik, soveel te meer waar langtermyn-kapitaalprojekte betrokke is.

Die aanvangsbelegging ten opsigte van 'n kapitaalprojek sluit die minste risiko van akkuraatheid in, aangesien dit op die tydstip van besluitneming bekend moet wees en weinig kan verander totdat die besluit gerealiseer het.

Die ander faktore wat noodsaaklik is vir besluitneming en in die toekoms gaan realiseer oor die leeftyd van die bate, is onderhewig aan die verandering in geldwaarde en is dit belangrik dat die invloed van dié verandering in berekening

Die invloed van pryspeilveranderinge kan in berekening gebring word deur die gebruik van algemene of spesifieke pryspeilveranderinge.

Die toepassing hiervan het daartoe gelei dat, slegs algemene pryspeilveranderinge, of slegs spesifieke pryspeilveranderinge, of algemene en spesifieke pryspeilveranderinge gebruik kan word vir die aansuiwering van items. Laasgenoemde sluit die voordele van die gebruik van beide pryspeilveranderinge in. By elk van hierdie toepassings, het daar verskillende metodes ont wikkel wat volgens groepering in beginsel ooreenstem, terwyl daar ten opsigte van die detail verskille in die toepassing kan ontstaan.

S.Afr. Tydskr. Bedryfsl. 1984, 15: 140-143

Sarah S. Viseer

Pretoriusstraat 14, Potchefstroom 2520, Republiek van Suid-Afrika

Aanvaar Junie 1984

\section{Inloiding}

Inflasie het 'n werklikheid geword waarmee saamgeleef en waarvoor beplan moet word. Inflasie, of te wel stygende pryse of dalende koopkrag, het hoofsaaklik sedert die sestigerjare momentum begin kry. Kapitaalinvesteringsbesluite is besluite wat geneem word vir die lang termyn (Clark, Hindelang \& Pritchard, 1979:3), gevolglik kan die daling in die koopkrag van geld ' $n$ invloed uitoefen op faktore wat in ag geneem word by die neem van sodanige besluite.

Kapitaalinvesteringsbesluite word geneem na inagneming van primêre en sekondêre faktore. Die primêre (belangrikste) faktore sluit in:

- Jaarlikse netto kontantvoordeel as gevolg van die belegging, en

- aanvangsbelegging.

Die sekondêre faktore sluit onder andere in:

- Slopingswaarde (reswaarde) aan die einde van die bate se leeftyd,

- kapitaalkoste (kritiese rentabiliteit) (Hamman \& Lambrechts, 1979:276,

- wins of verlies by vervreemding van die bate, en

- leeftyd.

Naas een sluit al bogenoemde faktore ' $n$ onsekerheidsfaktor in, aangesien dit gegewens is wat op die toekoms gebaseer is - die enigste faktor waaroor daar sekerheid bestaan is die aanvangsbelegging.

\section{Agtergrond van die metodes vir die inagneming van stygende pryspeilveranderinge}

Stygende pryspeilveranderinge kan hoofsaaklik op tweërlei wyse in ag geneem word, naamlik die inagneming van algemene pryspeile wat ' $n$ aanduiding is van die styging van pryse in die algemeen, en spesifieke pryspeile wat 'n aanduiding is van die styging van pryse van spesifieke items, wat in hierdie geval langtermynbates (vaste bates) sal wees.

Algemene en spesifieke pryspeilveranderinge word deur verskillende metodes toegepas om die invloed van inflasie in ag te neem. In teorie kom dit na vore dat die metodes van inagneming van inflasie in drie groepe groepeer kan word, naamlik:

(i) Metodes wat slegs algemene pryspeilveranderinge gebruik vir die aansuiwering van items;

(ii) metodes wat slegs spesifieke pryspeilveranderinge gebruik vir die aansuiwering van items, en

(iii) metodes wat beide algemene en spesifieke pryspeilveranderinge gebruik vir die aansuiwering van items (Backer, 1973:153). 
Onder eersgenoemde groep word genoem:

- Konstante koopkragrekeningkunde (constant purchasing power accounting) (Scapens, 1977:46), en

- huidige koopkragrekeningkunde of -metode (Visser, 1982:64) (current purchasing power accounting).

Aanhangers van hierdie metodes glo dat die invloed van inflasie in ag geneem moet word ten opsigte van die koopkrag van geld in die algemeen.

Die tweede groep waar hoofsaaklik van spesifieke pryspeilveranderinge gebruik gemaak word vir die inagneming van inflasie is:

- Huidige vervangingskostemetode of -rekeningkunde (current replacement cost accounting) (Visser, 1982:67),

- vervangingskosterekeningkunde (replacement-cost accounting, cost-replacement accounting) (Miller, 1980:143), en

- vervangingswaarderekeningkunde (replacement-value theory, stabilized accounting, revaluation accounting, common-dollar accounting) (Batty, 1982:706). Hierdie metodes maak veral gebruik van spesifieke pryspeile wanneer die markwaarde, aankoopprys of die waarde vanaf waardeerders moeilik bekombaar is.

Dic derde groep waar van beide algemene en spesifieke pryspeilveranderinge gebruik gemaak word vir die aansuiwering van items is:

- Huidige waarderekeningkunde (current-value accounting) (Chippindale \& Defliese, 1977:13), en

- huidige kosterekeningkunde (current-cost accounting) (Inflation Accounting Steering Group, 1977:43) wat insluit die Sandilandskomitee se aanbevelings, E.D. 18, en Standpunt 4.003, die belangrikste. Hierdie groep sluit die voordele van die 'gebruik van die algemene sowel as die voordele van die gebruik van die spesifieke pryspeilveranderinge in.

\section{Aansuiwering van koste gedurende 'n tydperk van stygende pryspeilveranderinge}

Die jaarlikse netto kontantvoordeel wat by die inleiding as een van die primêre faktore by kapitaalinvesteringsbesluite genoem is, en ook die enigste primêre faktor is waaroor daar onsekerheid bestaan, word bepaal of bereken na aanleiding van die netto wins. Die netto wins wat bereken word uit inkomste en koste (historiese of werklike) is nie 'n getroue weergawe van die stand van sake gedurende 'n tydperk van stygende pryse nie.

Om die netto wins te bepaal sodat dit 'n getroue weergawe is van die stand van sake, moet die koste aangesuiwer word na 'resente' koste wat by elk van die genoemde metodes ' $n$ ander waarde verteenwoordig. Hierdie verskil in waardes word veroorsaak as gevolg van die feit dat een groep slegs van algemene pryspeilveranderinge gebruik maak en gevolglik alle koste-items, d.i. materiaal, arbeid, kontantbokoste en waardevermindering deur middel van die algemene pryspeilverandering aansuiwer. Die tweede groep maak hoofsaaklik van spesifieke pryspeilveranderinge gebruik vir die aansuiwering van alle koste-items naamlik materiaal, arbeid, kontantbokoste en waardevermindering. Die derde groep maak hoofsaaklik van algemene pryspeilveranderinge gebruik vir die aansuiwering van materiaal, arbeid en kontantbokoste items, terwyl die spesifieke pryspeilveranderinge gebruik word vir die aansuiwering van waardevermindering.

Toepassing van die metodes vir die inagneming van stygende pryspeilveranderinge in die praktyk

Uit 'n ondersoek na ondernemings wat op die Johannesburgse Effektebeurs genoteer is, deur middel van vraelyste met 'n ewekansige steekproef van $22,7 \%$, het $34,17 \%$ daarop gereageer. Die responspersentasie was hoër as $34,17 \%$, maar som- mige vraelyste was nie bruikbaar nie, aangesien sommige ondernemings dit as 'nie van toepassing' beskou het. As gevolg van 'n bruikbare respons van $34,17 \%$, kan die afleidings uit die response nie veralgemeen word nie maar is slegs geldig ten opsigte van die ondernemings wat gerespondeer het.

Die volgende afleidings is gemaak uit die ondersoek ten opsigte van die ondernemings wat gerespondeer het (Visser, 1982:337-356):

By ' $n$ ontleding van die soort onderneming en die vraag of die invloed van inflasie in ag geneem word, het dit duidelik geblyk dat vervaardigingsondernemings en kleinhandelaars meestal inflasie in ag neem; ontginningsondernemings eweveel positief as negatief is vir die inagneming van inflasie; groothandelaars wel inflasie in ag neem; en by ander ondernemings (o.a. beleggingsmaatskappye, assuransiemaatskappye, banke, konstruksiemaatskappye, en hotelle) die meerderheid nie inflasie in ag neem nie. As geheel beskou neem twee-derdes van die ondernemings wat gerespondeer het, wel die invloed van inflasie in ag.

Uit 'n analise van die soort onderneming en die metode wat gebruik word vir die inagneming van inflasie, het dit na vore gekom dat:

- Vervaardigingsondernemings meestal gebruik maak van huidige kosterekeningkunde.

- Ontginningsondernemings slegs gebruik maak van huidige kosterekeningkunde.

- Groothandelaars eweveel gebruik maak van huidige kosterekeningkunde en huidige koopkragmetode.

- Kleinhandelaars meestal gebruik maak van vervangingskosterekeningkunde hoewel die konstante koopkragrekeningkunde en huidige koopkragmetode ook gebruik word.

- Ander ondernemings meestal gebruik maak van die konstante koopkragmetode, terwyl die huidige kosterekeningkunde, huidige koopkragmetode en vervangingskosterekeningkunde ook gebruik word.

- As geheel gesien, word die meeste gebruik gemaak van die huidige kosterekeningkunde.

By 'n ontleding van die soort onderneming en die vraag of inflasie in ag geneem word by die vasstelling van die verkoopprys is bepaal dat:

- Alle ondernemings meestal inflasie in ag neem by die vasstelling van die verkoopprys behalwe die ontginningsondernemings, waar die negatiewe antwoord die hoogste is. As geheel beskou neem $68,4 \%$ wel inflasie in ag by die vasstelling van die verkoopprys teenoor $31,6 \%$ wat dit nie in ag neem by die verkoopsprysvasstelling nie.

By 'n vergelyking tussen die soort onderneming en die metode van inflasiekoersaanpassing by die verkoopprys, kan afgelei word dat:

- Vervaardigingsondernemings en ander ondernemings meestal gebruik maak van spesifieke pryspeilveranderinge.

- Kleinhandelaars eweveel van kleinhandelsprysindekse en spesifieke pryspeilveranderinge gebruik maak en in 'n mindere mate van groothandelsprysindekse.

- Groothandelaars eweveel van spesifieke pryspeilveranderinge as ander metodes (o.a. verkoopprys-aanpassing op grond van die mark en 'n beraamde koers om aan te pas by kostestygings) gebruik maak.

- Ontginningsondernemings slegs van ander metodes gebruik maak.

- As geheel gesien, spesifieke pryspeilveranderinge die meeste $(59,3 \%$ teenoor $11,1 \%$ deur middel van groothandelsprysindekse, $14,8 \%$ deur middel van kleinhandelsprysindekse, en $14,8 \%$ deur middel van ander metodes) gebruik word 
vir die inflasiekoers aanpassing by die verkoopprys.

Uit ' $n$ analise van die soort onderneming en die vraag of rumateriaalkoste teen kosprys in berekening gebring word, was die reaksie soos volg:

- Vervaardigingsondernemings, kleinhandelaars en ander ondernemings meestal rumateriaalkoste teen kosprys in berekening bring.

- Groothandelaars rumateriaalkoste teen kosprys in berekening bring.

- Ontginningsondernemings rumateriaalkoste nie teen kosprys in berekening bring nie.

- As geheel, die meerderheid ondernemings (65,6\% teen $34,4 \%)$ wel rumateriaalkoste teen kosprys in berekening bring.

By 'n vergelyking van die soort onderneming en die metode wat gebruik word vir die bepaling van die uitreikingsprys van rumateriaalkoste het dit soos volg na vore gekom:

- Slegs vervaardigingsondernemings en kleinhandelaars meestal gebruik maak van die laaste-in-eerste-uit-metode.

- Ander ondernemings eweveel gebruik maak van die laastein-eerste-uit-metode as die eerste-in-eerste-uit-metode.

- Vervaardigingsondernemings meestal gebruik maak van die eerste-in-eerste-uit-metode.

- Groothandelaars geeneen van die metodes gebruik nie.

- As geheel, die laaste-in-eerste-uit-metode die meeste $(40 \%$ teenoor $26,7 \%, 13,3 \%, 6,7 \%, 13,3 \%$ ) gebruik word.

By 'n ontleding van die soort onderneming en die metode vir die bepaling van die eindvoorraadwaarde vir rumateriaal/ handelsartikels was die respons soos volg:

- Vervaardigingsondernemings, kleinhandelaars en ander ondernemings meestal gebruik maak van die eerste-ineerste-uit-metode.

- Ontginningsondernemings en groothandelaars slegs van die laaste-in-eerste-uit-metode gebruik maak.

- As geheel gesien, die meeste gebruik gemaak word van die eerste-in-eerste-uit-metode $(40 \%$ teenoor $34,3 \%, 2,9 \%$, $5,7 \%$ en $17,1 \%$ ).

Wat egter opvallend is uit die voorafgaande twee analises, is dat die meerderheid ondernemings die laaste-in-eerste-uitmetode gebruik vir ' $n$ uitreikingsprys terwyl die meerderheid ondernemings die eerste-in-eerste-uit-metode gebruik vir die bepaling van die eindvoorraadwaarde vir rumateriaal/handelsartikels. Die gebruik van die laaste-in-eerste-uit-metode vir die bepaling van die uitreikingsprys, dui op 'n 'resente' koste gedurende ' $n$ tydperk van stygende pryse, aangesien die pryse van laaste aankope die hoogste is. Die gebruik van die eerstein-eerste-uit-metode vir die bepaling van die eindvoorraadwaarde bring mee dat gedurende ' $n$ tydperk van stygende pryse die eindvoorraadwaarde volgens die eerste-in-eerste-uit-metode hoër is as wanneer die laaste-in-eerste-uit-metode gebruik word, wat 'n meer 'resente' waarde vir die eindvoorraad weergee. 'n Hoër eindvoorraad gaan 'n hoër wins meebring wat 'n volgende vraag kan meebring. Is daardie wins 'n getroue weergawe van die stand van sake?

In 'n analise tussen die soort onderneming en die metode wat toegepas word vir die inagneming van inflasie by die vergoeding van arbeid, is die volgende afleidings moontlik:

- Vervaardigingsondernemings en kleinhandelaars maak meestal gebruik van spesifieke pryspeilveranderinge.

- Ontginningsondernemings maak meestal gebruik van kleinhandelsprysindekse.

- Groothandelaars maak eweveel van spesifieke pryspeilveranderinge as ander metodes gebruik.

- Ander ondernemings maak meestal van ander metodes (o.a. bestuursfooie, huidige markkoerse, statutêr en op- meriete-basis aanpassings en onderhandeling) as groothandels-, kleinhandelsprysindekse, en spesifieke pryspeilveranderinge gebruik.

- As geheel gesien, word ander metodes die meeste gebruik vir die inagneming van inflasie by die vergoeding van arbeid.

'n Volgende vergelyking is gedoen tussen die soort onderneming en die metode van inagneming van inflasie by vervaardigingsbokoste. Van die ondernemings wat gereageer het, maak:

- Vervaardigingsondernemings meestal gebruik van spesifieke pryspeilveranderinge.

- Groothandelaars eweveel van spesifieke pryspeilverande ringe as ander metodes gebruik.

- Kleinhandelaars eweveel van groothandelsprysindekse, spesifieke pryspeilveranderinge en ander metodes gebruik.

- Ontginningsondernemings eweveel van groothandelsprysindekse as spesifieke pryspeilveranderinge gebruik.

- Ander ondernemings meestal van spesifieke pryspeilveranderinge gebruik.

- As geheel 50\% van die ondernemings van spesifieke pryspeilveranderinge vir die aansuiwering van vervaardigingsbokoste, gebruik.

In ' $n$ analise tussen die soort onderneming en die metode van inagneming van inflasie by na-vervaardigingsbokoste was die reaksie dieselfde as by bogenoemde (vervaardigingsbokoste) met die uitsondering van kleinhandelaars, wat meestal gebruik maak van spesifieke pryspeilveranderinge en ander metodes (o.a. periodieke herberekening, en groothandels- en kleinhandelsprysindekse gekombineer.)

By 'n ontleding van die soort onderneming en die reaksie op die vraag of die invloed van inflasie met betrekking tot vaste bates by die boekwaarde van die bate of by waardevermindering getoon word, kan die volgende afleidings gemaak word:

- Vervaardigingsondernemings doen meestal die aansuiwering by die boekwaarde.

- Groothandelaars doen eweveel die aansuiwering by die boekwaarde as by waardevermindering.

- Ontginningsondernemings, kleinhandelaars, en ander ondernemings doen die aansuiwerings meestal anders as bogenoemde twee.

- As geheel, ander metodes (o.a. vervangingsreserwes en herwaardasie van vaste bates elke twee jaar) word die meeste toegepas vir die aansuiwering van inflasie by vaste bates. By 'n vergelyking tussen die soort ondernemings en die belangrikste maatstawwe wat gebruik word by besluite vir belegging in vaste bates, het dit na vore gekom dat:

- Alle ondernemings meer as een maatstaf gebruik naamlik dié wat die tydwaarde van geld in ag neem, asook dié wat die tydwaarde van geld ignoreer. As geheel was dit duidelik dat daar meestal van meer as een maatstaf gebruik gemaak word.

- Die reaksie op die vraag of die invloed van inflasie in ag geneem word by die neem van kapitaalinvesteringsbesluite het dit na vore gekom dat by alle ondernemings die meerderheid positief geantwoord het.

In ' $n$ analise tussen die soort onderneming en die vraag of die invloed van inflasie in berekening gebring word by kapitaalkoste, kan afgelei word dat:

- Slegs vervaardigingsondernemings en groothandelaars meestal die invloed van inflasie in berekening bring by kapitaalkoste, terwyl al die ander ondernemings dit nie doen nie. As geheel beskou, word die invloed van inflasie meestal nie in berekening gebring by kapitaalkoste nie. 


\section{Afleidings on aanbevelings}

Die belangrikste faktor (soos genoem by die inleiding) wat in ag geneem word by die neem van investeringsbesluite en waaroor daar onsekerheid bestaan vanweë die toekomsgebondenheid, is die jaarlikse netto kontantvoordeel. Om by hierdie syfer uit te kom is dit noodsaaklik, soos blyk uit die literatuur en praktyk, dat die verkopesyfer asook die kostesyfers, dit is materiaal, arbeid, kontantbokoste, en waardevermindering, aangesuiwer moet word om uiteindelik by 'n netto wins en netto kontantvoordeel te kom wat 'n getroue weergawe van die stand van sake sal wees. Die spesifieke wyse waarop aansuiwering geskied, sal afhang van die metode van inflasierekeningkunde in die betrokke onderneming.

Die ander sekondêre faktore wat in ag geneem word by die neem van investeringsbesluite is:

(a) Slopingswaarde. Aangesien hierdie bedrag in die toekoms ontvang gaan word, sal stygende pryspeile ' $n$ invloed hierop uitoefen maar die invloed is moeilik bepaalbaar vanweë die feit dat die datum van vervreemding onderhewig is aan tegnologiese ontwikkelings, uitbreiding aan produksievereistes, en so meer.

(b) Kapitaalkoste. Uit die literatuurstudie het dit geblyk dat die beskikbaarheid van kapitaal beinvloed kan word deur prysstygings wat gevolglik ook ' $n$ invloed op die koste van kapitaal uitoefen (Carsberg \& Hope, 1976: 25). Uit die empiriese ondersoek in die praktyk het dit na vore gekom dat die invloed van inflasie by die meerderheid ondernemings nie in ag geneem word by kapitaalkoste nie. Ondernemings kan van mening wees dat die kontantvloeibedrae aangesuiwer word na bedrae van gelyke koopkrag en die invloed van inflasie op kapitaalkoste buite rekening gelaat word.

(c) Wins of verlies by vervreemding. Hierdie bedrag, wat bepaal word uit die verskil tussen die boekwaarde en verkoopswaarde (vervreemdingswaarde), is weer onderhewig aan die tyd van vervreemding wat baie moeilik vooruitbepaalbaar is.

(d) Leeftyd. Die vooruitskatting van die leeftyd van 'n bate is 'n probleem aangesien niemand met sekerheid vooruit kan bepaal hoe lank ' $n$ bate ekonomies kan produseer nie en daar ook faktore buite die beheer van die bestuur is, bv. tegnologiese ontwikkelinge, hoë onderhoudskoste wat sloping noodsaak, die beëindiging van 'n produklyn, en die uitbreiding van kapasiteit.

\section{Summary}

Capital investment decisions are taken with due regard for primary and secondary factors. The primary factors include:

- Annual net cash gain as a result of the investment; and

- initial investment.

The secondary factors include, amongst others:

- Residual value;

- capital cost;

- profit or loss upon alienation of the asset; and

- lifespan.

The only element among the above about which there is any certainty is the initial investment. The rest of the factors are futuredirected and subject to change in the value of money. The consideration of rising price-level changes has thus become essential.

The methods used for the consideration of rising price levels are mainly divided into three groups, namely:

(i) Methods using only general price level changes;

(ii) the methods using only specific price level changes; and

(iii) the methods using both general and specific price level changes for the adjustment of items.

In each of the three groups mentioned there are applications known as different methods. Among the first group are constant purchasing power accounting and current purchasing power accounting.

Among the second group, where specific price level changes are used for the discounting of inflation, one finds:

- Current replacement cost accounting;

- replacement cost accounting; and

- replacement value accounting.

The third group, using both general and specific price-level changes for the adjustment of items includes:

- Current value accounting; and

- current cost accounting which includes, amongst others, the recommendations of the Sandilands Committee, E.D. 18 , and Guideline 4.003 .

Because the annual net cash gain, as a result of the investment, is the only primary factor about which there is uncertainty, it is important that the influence of increasing pricelevel changes be reflected in it. The annual net cash gain is put together from components such as sales, cost (cash expenditures, e.g. material, labour, and overheads, as well as non-cash overheads, e.g. tax savings on depreciation) and income tax. As a result of this the annual net cash gain in the three different main groups (outlined above) will differ because of the fact that either general or specific price-level changes, or both, are used for the adjustment of items.

Accordingly the application of the methods for the consideration of rising price-level changes in practice is discussed with reference to an empirical study undertaken among quoted enterprises on the Johannesburg Stock Exchange.

\section{Venwysings}

Backer, M. 1973. Current value accounting. New York: Financial Executives Research Foundation.

Batty, J. 1982. Management accountancy. Sth edition. London: MacDonald \& Evans.

Carsberg, B. \& Hope, A. 1976. Business investment decisions under inflation; theory and practice. London: Institute of Chartered Accountants in England and Wales.

Chippindale, W. Defliese, P.L. 1977. Current value accounting: $A$ Practical guide for business. New York: Amacon.

Clark, J.J., Hindelang, T.J. \& Pritchard, R.E. 1979. Capital budgeting; planning and control of capital expenditures. Englewood Cliffs: Prentice-Hall.

Hamman, W.D. \& Lambrechts, I.J. 1979. Inflasie en die investe ringsbes/uit. (In Lambrechts, I.J., Reynders, H.J.J. \& Scheurkogel, A.E. (Red.) Die investeringsbesluit. Pretoria: HAUM. p. 274-294).

Inflation Accounting Steering Group. 1977. Guidance manual on current cost accounting including the Expasure Draft. London: Tolley.

Miller, E.L. 1980. Inflation accounting. New York: Van Nostrand Reinhold.

Scapens, R.W. 1977. Accounting in an inflationary environment. London: Mac Millan.

Visser, S.S. 1982. Die invloed en toepassing van pryspeilveranderinge by kapitale beleggingsbesluite. (Proefskrif (D.Comm.). PU vir CHO). 